\title{
Estimating dynamics of fern species richness and assemblages for 30 years in Japan capital and along planning belt of linear motor car from Tokyo to Nagoya
}

\begin{abstract}
We surveyed species density of ferns in Musashi (Tokyo and Saitama Prefs.), around capital of Japan, and planning belt of Linea express of 250km from Tokyo to Nagoya during 1997-2017, considering with records 30 years (mainly 1960-1980). The species richness (species richness per $10 \mathrm{~km} \mathrm{X} \mathrm{10km)} \mathrm{and} \mathrm{similarity} \mathrm{of} \mathrm{species} \mathrm{assemblages}$ represented by species overlap were recorded and calculated between them of the past and present. Recent species richness is about half or less and the similarity ranged $0-48 \%$ in Musashi and $20-50 \%$ in the similarity along the Linea express planning belt.

a. The species richness is much decreased in Musashi and the Linea express planning belt in the temperate in southern Honshu.

b. The similarity of species assemblages ranged $0-50 \%$ for 30 years.

c. The fern flora might be affected by the human activity than the climatic warming in the temperate region of Japan.
\end{abstract}

Keywords: climatic warming; fern species, vegetation, earthquake destruction, mountain regions, linear motor car
Volume 2 Issue 2 - 2018

Toshiyuki Sato,' Yasutake Sugawara, ${ }^{2}$ Ryosuke

Matsuura,' Shinpei Hasegawa,' Takayuki

Tanaka ${ }^{3}$

'Faculty of Science, Shinshu University, Japan

${ }^{2}$ Faculty of Science, Saitama University, Japan

${ }^{3}$ Gakuyo High School of Nagano Prefecture, Japan

Correspondence: Toshiyuki Sato, Faculty of Science, Shinshu University, Matsumoto, Japan, Email toshibo@shinshu-u.ac.jp

Received: November 14,2017 | Published: March 13, 2018

\section{Introduction}

Global climatic change is considered to influence on vegetation cover and richness at summit of mountains over the world ${ }^{1}$ during some centuries. Revegetation processes have been recorded on the bare ground or slopes by large volcanic eruption ${ }^{2}$ during decades of years. Strong impacts by human activity on vegetation dynamics are of course exist every day and everywhere over the world, however actual monitoring record is not much introduced since numerous events occur in various levels in time and space. ${ }^{3}$ Here we introduce possible dynamics of species richness and assemblages of ferns based on the database in Japan archipelago and re-survey data in a same intensity resolution, since central Honshu (central Japan) is now facing to rapid urbanization, nuclei pollution, earthquake destruction, and expecting new super Linear express construction with long tunnels.

Japan Archipelago consists of over 1000 fern and lycophytes taxa and variety and putative hybrids, as well as one of highest hotspot of biodiversity in eastern Asia. ${ }^{4,5}$ Recent Higashi-Nihon Tsunami and Radioactive flux pollution by Tokyo electric company induced by large earthquakes (magnitudes 6-8) at Eastern Honshu island facing to Pacific Ocean on 3.11, 2011. Japan Archipelago has geographically long been faced to many earthquakes with volcanic activities and climatic many typhoons of every year. As a result of these repeated natural disturbances, recent species richness and species richness might be recruited in small islands. ${ }^{6}$

Recent quick climatic changes such as winter warming in a recent century (Figure 1) and concentration of individuals in the capital regions and construction of highways and under construction belt for Linear motor express car from Tokyo to Nagoya until 2026 may suffer fern species extinction in the mountain regions (Figure 2). Here we report recent species density of fern species and species assemblage dynamics for over 30 years around capital in the central Japan (Musashi) and side of Tokai-Do pass waiting the highest magnitude technology underlay (Figure 2).

In next decades after accomplishment Linear motor car belt connected by tunnels, we expect little destruction of forests in southern Honshu, since Southern Japan Alps is the area as refusia in Japan Archipelago.

\section{Meteorological data}

Annual mean temperatures of the monthly maximum and minmum is shown in Figure 1 after Japan Meteorological Station Data during 1876 and 2017 (www. data. jma. go. jp/ etrn/view/monthly).

\section{Methods}

In a micro sites of $100 \mathrm{~m} \times 100 \mathrm{~m}$, only $33.3 \%$ of species assemblages was maintained in the temperate regions in Japan for 33 years, and another example showed $71 \%$ maintained in sub-arctic and cool temperate in the northernmost island Hokkaido for 20-30 years. ${ }^{7}$

Here we surveyed phyto-diversity of fern and fern allies these 20 years in central Japan, particularly Musashi (Saitama and Tokyo land area) and Linea planning belt from Tokyo and Nagoya, now in progress under construction of long tunnels below the mountain regions in Southern Honshu, where the highest fern species density was recorded in Central Honshu 1950-1995, ${ }^{8-15}$ as well as higher number of flowering plants consisted of cryo-plants (circumpolar and Himalaya mountain) and warm-temperate (South-eastern Asia) elements. ${ }^{16,17}$ 


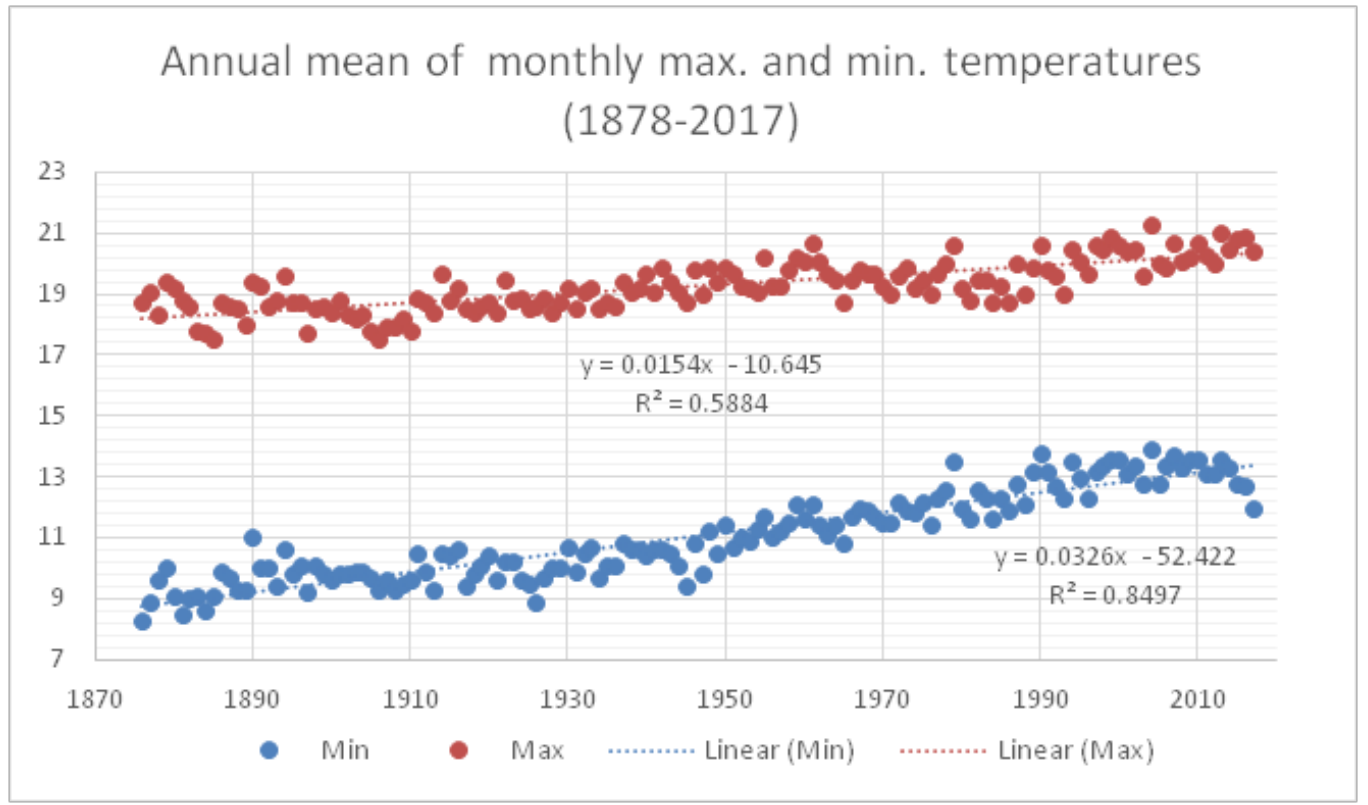

Figure I Meteorological data of annual mean of monthly maximum and minimum temperatures in Tokyo during I876 and 2017.

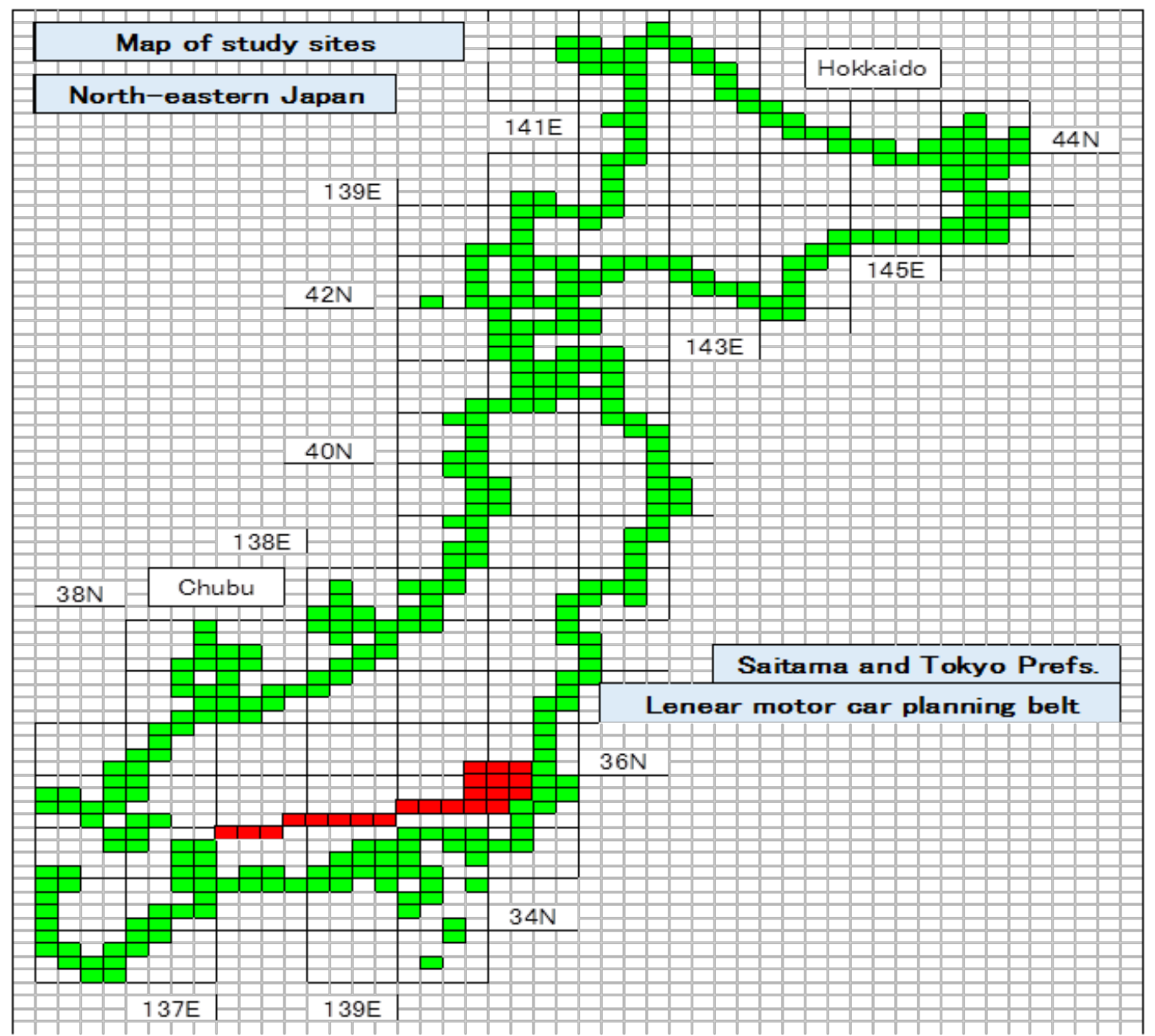

Figure 2 Study area of fern species density and assemblages of the past and present in the transitional regions from cool and warm temperate in Japan. Map of study area of past and present 


\section{Result}

Eastern Musashi cells showed the lower number of species amounted and the lower similarity of species assemblages are shown in Figure 4. Central west cells showed over 100 species have been recorded. Western cells showed rather higher similarity over $30 \%$ (Figure 5).
Total number of fern species recorded until 2017 and similarity (\%) of species assemblages between -1995 and -2017 were shown in Figure 6. The highest number of fern species density is about $150 \mathrm{spp}$. $/ 10 \mathrm{~km}$ X $30 \mathrm{~km}$ at 20 at western Tokyo, where the lowest similarity of less than $15 \%$ was recorded, since prompt urbanization had been held these years.

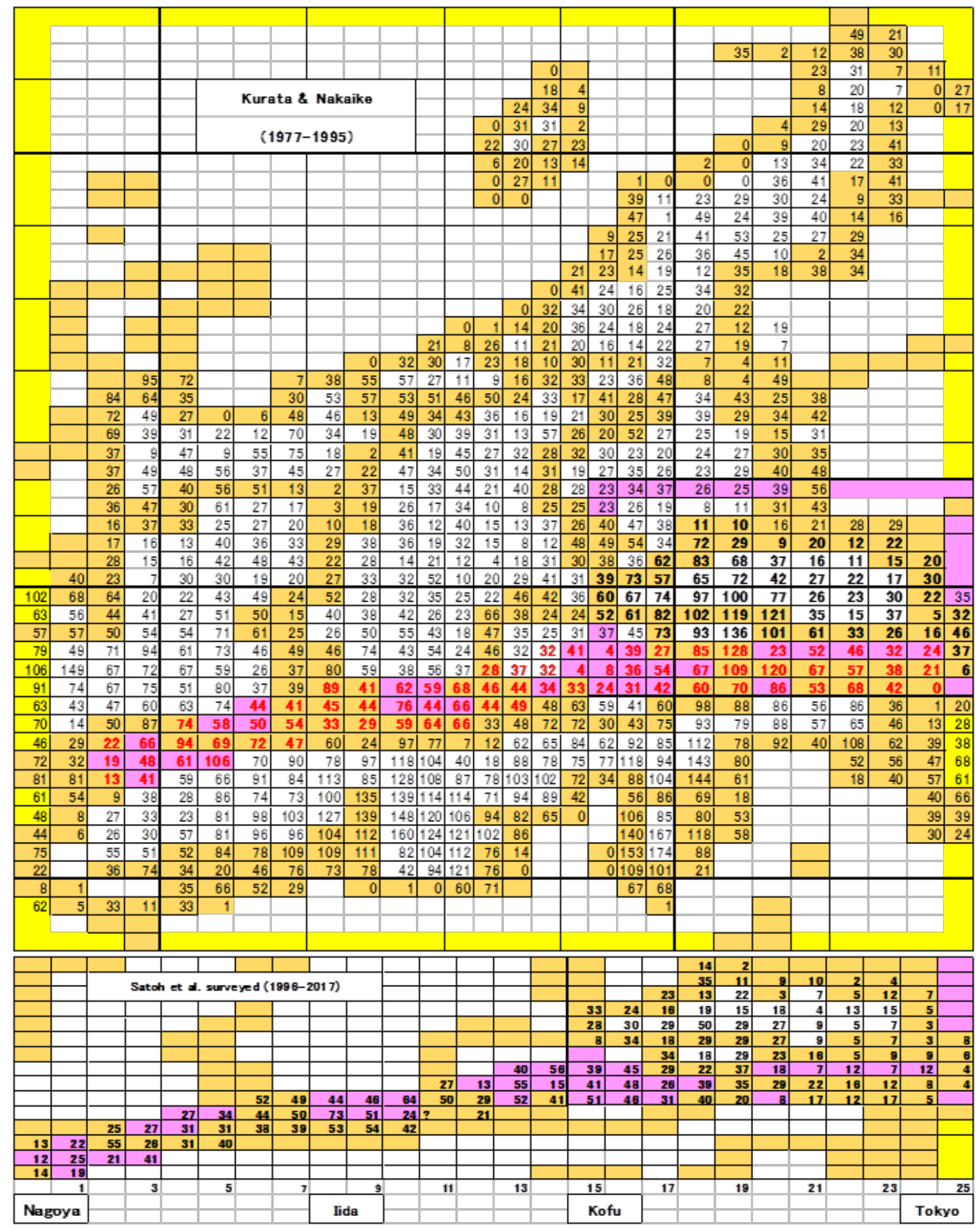

Figure 3 Distribution of fern species density reported by Kurata and Nakaike (1979-1997) and surveyed fern species density by present authors (Satoh et al. ${ }^{\circ}$ ) in Central Honshu, Japan. Part of this data is reserved in the Appendix 1A \& 1B. 


\begin{tabular}{|c|c|c|c|c|c|c|c|c|c|c|}
\hline & & & 22 & 10 & & & & & & \\
\hline & & & 78 & 31 & 15 & 24 & 13 & 23 & & \\
\hline & & 65 & 83 & 69 & 39 & 19 & 14 & 21 & 21 & \\
\hline 49 & 76 & 60 & 66 & 82 & 45 & 33 & 23 & 21 & 32 & \\
\hline 72 & 78 & 90 & 103 & 101 & 80 & 27 & 29 & 36 & 24 & \\
\hline 56 & 68 & 85 & 110 & 120 & 128 & 39 & 17 & 38 & 6 & 37 \\
\hline & & 79 & 93 & 136 & 105 & 65 & 36 & 27 & 19 & 47 \\
\hline & & & 86 & 133 & 30 & 53 & 50 & 32 & 28 & 38 \\
\hline & & & & 112 & 121 & 70 & 57 & 40 & 21 & 10 \\
\hline & & & & & & 60 & 69 & 47 & 5 & \\
\hline \multicolumn{11}{|c|}{ Musashi Total (-1995-2017) } \\
\hline & & & 0.14 & 0.2 & & & & & & \\
\hline & & & 0.37 & 0.29 & 0.2 & 0.25 & 0.08 & 0.13 & & \\
\hline & & 0.29 & 0.16 & 0.3 & 0.03 & 0.21 & 0.14 & 0.29 & 0.29 & \\
\hline 0.44 & 0.28 & 0.22 & 0.27 & 0.38 & 0.31 & 0.18 & 0.17 & 0.19 & 0.12 & \\
\hline 0.32 & 0.48 & 0.36 & 0.29 & 0.14 & 0.19 & 0.11 & 0.24 & 0.25 & 0.13 & \\
\hline \multirow[t]{5}{*}{0.4} & 0.34 & 0.29 & 0.38 & 0.23 & 0.16 & 0.13 & 0.11 & 0.16 & 0.33 & 0.08 \\
\hline & & 0.34 & 0.19 & 0.21 & 0.17 & 0.19 & 0.09 & 0.25 & 0.32 & 0.11 \\
\hline & & & 0.24 & 0.24 & 0.37 & 0.11 & 0.14 & 0.22 & 0.2 & 0.08 \\
\hline & & & & 0.29 & 0.21 & 0.27 & 0.28 & 0.25 & 0.38 & 0 \\
\hline & & & & & & 0.19 & 0.16 & 0.26 & 0 & \\
\hline \multicolumn{4}{|l|}{ Musa } & & & & & & & \\
\hline
\end{tabular}

Figure 4 Total fern species density and similarity of fern species assemblages during over 30 years between I950-I995 and I996-20I7 in Musashi district (Saitama and Tokyo prefs.) Appendix-IA \& IB for species assemblages and species lists.

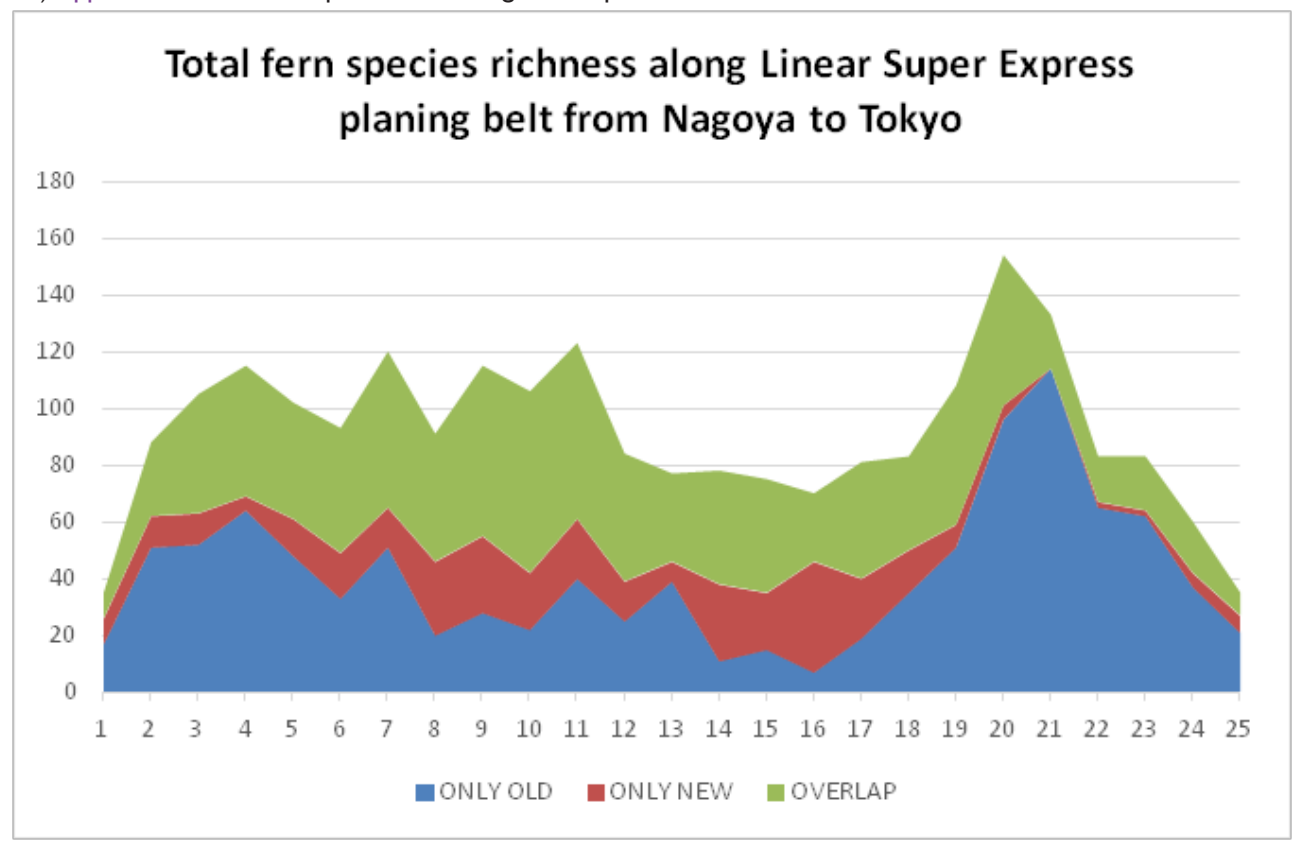

Figure 5 Fern species richness of the past, the present and the total along Linear motor car planning belt from Nagoya to Tokyo (about 250km). 


\section{Total species richness and overlap(\%) dynamics for 30 years from Nagoya to Tokyo Linea Belt}

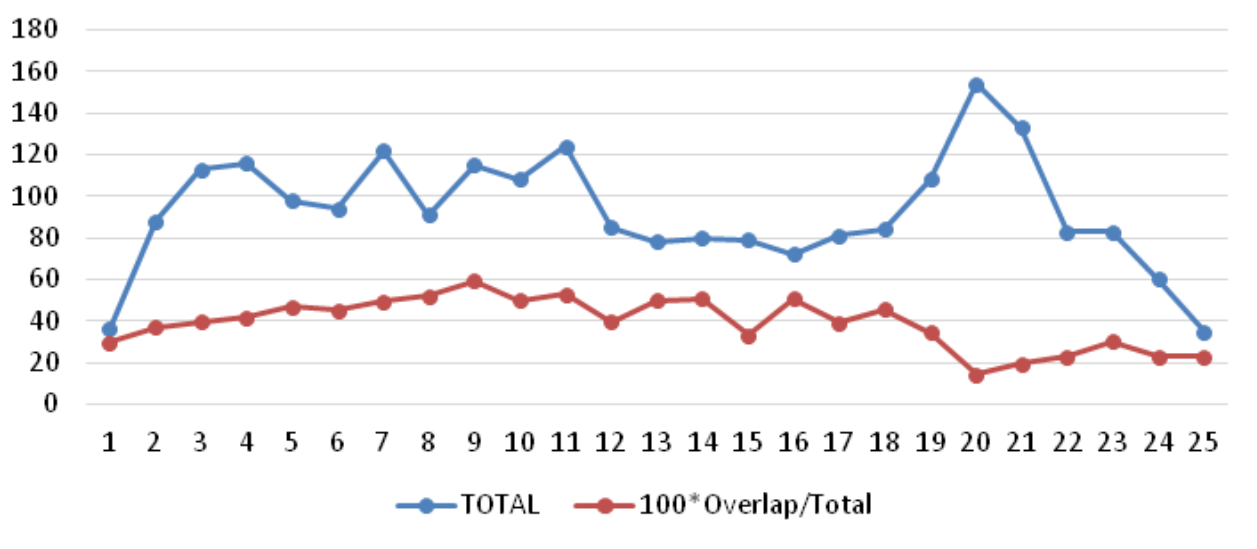

Figure 6 Total species richness and percentages (\%) of overlap species.

\section{Discussion}

Unexpected decrease of number of species per area of $10 \mathrm{~km} \mathrm{X}$ $10 \mathrm{~km}$ is recorded by present survey during 20 years. Western Musashi (Tokyo and Saitama) and eastern Aichi (Nagoya) showed abrupt decrease of species richness, however central Yamanashi and southern Nagano showed slightly increments of species richness.

Considered from recent warming tendency, we might expect migration of warm-temperate and subtropical element of ferns into the Musashi. Much decreasing of fern species richness (Figure 3) might be caused by human activity and urbanization. In next decades after Linear motor car belt connected by tunnels, we expect little destruction of forests in southern Honshu, since Southern Japan Alps is the area as refusia in Japan Archipelago.

Vegetation dynamics represented by richness and floristic elements can be explained by global climatic change (A), successional aspect (B) and prompt destruction by human impacts with local warming (C).

In the case of warming, fern species density is expected to be higher in Japanese Archipelago, since subtropical and warm temperate regions have higher species density compared with that of cool temperate and sub-arctic regions. In the record of 1950-1996, western Musashi showed over 100 species density, however recent records showed about half of the species density. These phenomena might be not caused by the global climatic warming (A) but be caused by human urbanization and habitat destruction (C) particular in the western part of Musashi as well as belt for Linea super express planning sites. Considered from an empirical data of some local fern assemblage maintained $33.3 \%$ similarity, ${ }^{6}$ life history of ferns starting from spore dispersal, gametophyte survival and development into sporophytes, exhibits unexpected speedy dynamics of fern assemblage in a local floristic composition. Fern compositions suggest the initiative dynamics of successional processes of the area (B). Soil and rocky surface texture might be critical for spore germination and gametophyte development before sporophyte development associated with forest structure and local weather conditions.

\section{Acknowledgements}

We express sincere thanks to editorial office for the invitation of this paper submission and many comments. The discussion about possible warm-temperate fern migration into Musashi during 30 years under warming is owed to the Chubu Ecological meeting 2017 at Niigata.

\section{Conflicts of interest}

Unexpected dynamics of fern species richness and assemblages is detected during some decades by the prompt urbanization with soil surface destruction by human activity, may be not by gentle climatic warming and successional dynamics of forest, since species richness decreases in most sites of regions from warm to cool temperate.

\section{References}

1. Grabher G, Gottfried M, Pauli H. Climate effects on mountain plants. Nature. 1994;369(6480):448.

2. Moral RD. Vegetation dynamics in space and time: an example from Mount St.Helens. Journal of Vegetaion Science. 2007;18(4):479-488.

3. Herbert S.Human-caused impact on preserved vegetation. Landscape and Urban Planning. 2004;68(4):347-355.

4. Ebihara J. The standard of ferns and lycophytes in Japan I. Japan: Gakken Plus; 2016. 475 p.

5. Ebihara J. The standard of ferns and lycophytes in Japan II. Japan: Gakken Plus; 2017. 500 p.

6. Satoh T, Tsuyuzaki S, Yoshida S. Ferns maintained 33.3\% of species assemblages for 33 years at 3 locations in the temperate of Japan. Bulletin of the Botanical Society of Nagano. 2017;50:95-99.

7. Satoh T. Dynamics of members and number of participants to the meeting of of Botanical Society of Nagano for 50 years. Bulletin of the Botanical Society of Nagano. 2017;50:43-50.

8. Kurata M, NakaikeT. Illustration and dictionary of pteridophytes of Japan 1. Japan: University of Tokyo Press; 1979. 628 p.

9. Kurata M, Nakaike T. Illustration and dictionary of pteridophytes of Japan 2. Japan: University of Tokyo Press; 1981. 648 p. 
10. Kurata M, NakaikeT. Illustration and dictionary of pteridophytes of Japan 3. Japan: University of Tokyo Press; 1983. 728 p.

11. Kurata M, Nakaike T. Illustration and dictionary of pteridophytes of Japan 4. Japan: University of Tokyo Press; 1985. 850 p.

12. Kurata M, Nakaike T. Illustration and dictionary of pteridophytes of Japan 5. Japan: University of Tokyo Press; 1987. 816 p.

13. Kurata M, Nakaike T. Illustration and dictionary of pteridophytes of Japan 6. Japan: University of Tokyo Press; 1990. 881 p.
14. Kurata M, Nakaike T. Illustration and dictionary of pteridophytes of Japan 7. Japan: University of Tokyo Press; 1994. 409 p.

15. Kurata M, Nakaike T. Illustration and dictionary of pteridophytes of Japan 8. Japan: University of Tokyo Press; 1997. 473 p.

16. Koizumi H. Relic cryo-plant zone in the southern Alps of Japan. Japan: Report of relic monuments in Nagano; 1926. 1-150 p.

17. Shimizu T. Flora of Nagano Prefecture. Japan: Shinano-Mainichi Publishes; 1997. 1735 p. 